\title{
Assessing the Investment Attractiveness of Renovation
}

\author{
Zharikov I.S. \\ Belgorod State Technological University named after V.G. Shukhov \\ Belgorod, Russia \\ igor_bgtu@mail.ru
}

\begin{abstract}
The widespread use of mathematical methods is the most important area of improving economic analysis, increasing the effectiveness of the analysis of the organizational activities of investment in the renovation of real estate. One of the most effective tools for implementing the mathematical problem of economic analysis is factor analysis. Factor analysis is a gradual transition from the initial factor system to the final system of factors, the disclosure of a set of quantitatively measured factors that influence the change in the effective indicator. In the presence of many different factors affecting the investment attractiveness of renovation, it is advisable to apply regression analysis. The regression equations and indicators of statistical significance obtained in the work allow suggesting the feasibility and sufficiency of the set of technical and urban planning factors of the renovated property accepted for analysis to obtain reliable estimates of the potential capitalization of the investment and construction project of the renovated real estate. The established close relationship between the variable factors and investment indicators of renovation allows effectively, through the implementation of the proposed regression equation, determining the economic efficiency of the renovated object.
\end{abstract}

Keywords - investment, efficiency, renovation, factor analysis, regression.

\section{INTRODUCTION}

The implementation of mathematical methods in determining the economic efficiency of investment in the renovation of real estate is cost-effective with full coverage of the influence of factors on the results of commercial, investment and financial activities of renovation work, replacing simplified or approximate calculations with exact calculations, setting and solving new multidimensional analysis problems almost impossible to do manually or by traditional methods. One of the ways to solve the formulated mathematical problem of economic analysis is factor analysis.

In the direct factor analysis, individual factors are identified that have an effect on the change in the effective indicator, in this case, the studied set of technical and town-planning characteristics of the renovation object that are studied is appropriate and sufficient for analysis, the forms of functional or stochastic dependence between the values of investment indicators and a certain set of factual factors are established and, finally, the role of individual factors in changing the effective investment indicator of capitalization of real estate renovation.

\section{RESULTS}

In [1], the author performed a quantitative assessment of the factor space for the subject of research - an assessment of the investment attractiveness of renovating a building (structure), as a result of which it was concluded that the direction of renovation of the building (structure) should be expedient for its subsequent implementation as a commercial, residential or social purpose. In [2], the author proposed a modified calculation of the discount rate for renovation facilities and proposed a methodology for calculating investment indicators of renovation. Based on the developed organizational and methodological model of the risk environment, taking into account the adjusted discount rate and the methodology for assessing investment attractiveness with the choice of the most cost-effective functional purpose, a field experiment was performed: for 17 objects, potentially requiring measures for their renovation, cash flow plans were constructed (Table 1), which revealed the representativeness of the experimental results in the table:

TABLE I. RESULTS OF THE FULL-SCALE EXPERIMENT

\begin{tabular}{|l|l|l|l|l|l|l|l|l|}
\hline $\mathbf{N}$ & $\mathbf{D P I}$ & $\mathbf{D P P}$ & \multicolumn{1}{|c|}{$\mathbf{N P V}$} & $\mathbf{D I R R}$ & $\mathbf{I I I A}$ & \multicolumn{1}{|c|}{$\mathbf{Z}$} & $\mathbf{R}_{\text {peн }}$ & RIRR \\
\hline 1 & 2.22 & & 825.313 & 25.9 & 57.7 & 46.2 & 13.158 & 1.97 \\
\hline 2 & 2.65 & 7 & 83.66 & 27.3 & 48.45 & 30.19 & 11.7171 & 2.33 \\
\hline 3 & 1.9 & 4 & 10.82 & 25.1 & 52.1 & 34.59 & 12.1131 & 2.078 \\
\hline 4 & 1.79 & 4 & 12.75 & 22.9 & 66.5 & 33.25 & 12.325 & 1.86 \\
\hline 5 & 2.15 & 7 & 67.94 & 23.5 & 50.8 & 29.25 & 11.925 & 1.97 \\
\hline 6 & 1.9 & 2 & 33.4 & 25.5 & 57.4 & 42.71 & 12.8439 & 1.98 \\
\hline 7 & 2.31 & 8 & 129.9 & 25.6 & 54.15 & 38.18 & 12.4362 & 2.06 \\
\hline 8 & 2.84 & 6 & 332.19 & 30.2 & 70.95 & 39.88 & 12.5892 & 2.4 \\
\hline 9 & 3.64 & 5 & 2039.4 & 35.7 & 80.25 & 36.86 & 12.3174 & 2.9 \\
\hline 10 & 3.96 & 5 & 10807.77 & 38.8 & 81.85 & 39.78 & 12.5802 & 3.08 \\
\hline 11 & 2.38 & 7 & 423.38 & 27.2 & 62.55 & 44.68 & 13.0212 & 2.09 \\
\hline 12 & 2.86 & 6 & 195.47 & 30.7 & 70.8 & 41.74 & 12.7566 & 2.41 \\
\hline 13 & 2.55 & 7 & 188.721 & 29.9 & 70.15 & 51.69 & 13.6521 & 2.19 \\
\hline 14 & 3.66 & 5 & 32.98 & 34 & 60.6 & 27.76 & 11.4984 & 2.96 \\
\hline 15 & 2.08 & 9 & 66.16 & 23.3 & 49.7 & 35.64 & 12.2076 & 1.91 \\
\hline 16 & 3.89 & 5 & 420.61 & 36.5 & 64.85 & 31.32 & 11.8188 & 3.09 \\
\hline 17 & 2.75 & 6 & 255.21 & 30.5 & 61.25 & 46.01 & 13.1409 & 2.32 \\
\hline
\end{tabular}

For clarity of the data obtained, we reflect the results in the graphs of the dependence of investment indicators on IIIA values (Figs. 1-6).

From the compiled graphs, it can be seen that most of the relationships have a positive result, which indicates a direct relationship between IIIE and investment indicators. The closest relationship is seen between IIIE and DPI, NPV, IRR, which means that the integral indicator of investment 
attractiveness of the factor space of renovation, and, accordingly, individual technical and urban characteristics (factors) of renovation objects, have the greatest impact on the profitability, profitability and investment reliability of renovation REI [3].

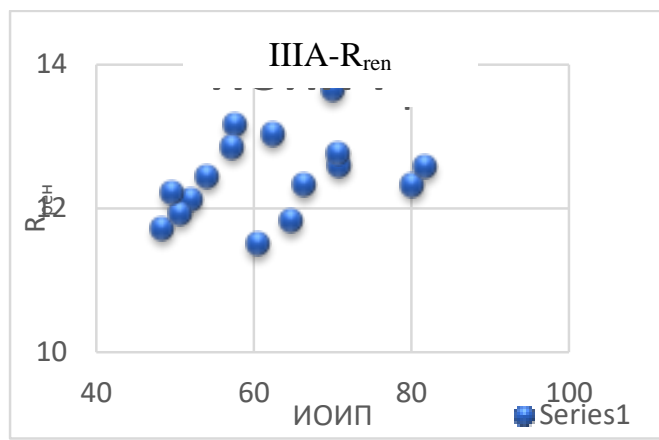

Fig. 1. REI discount rate of renovation objects vs. IIIE

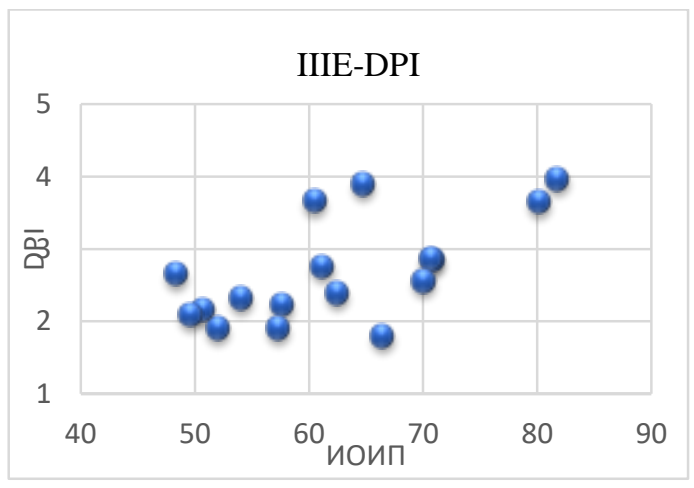

Fig. 2. REI profitability of renovation objects vs. IIIE

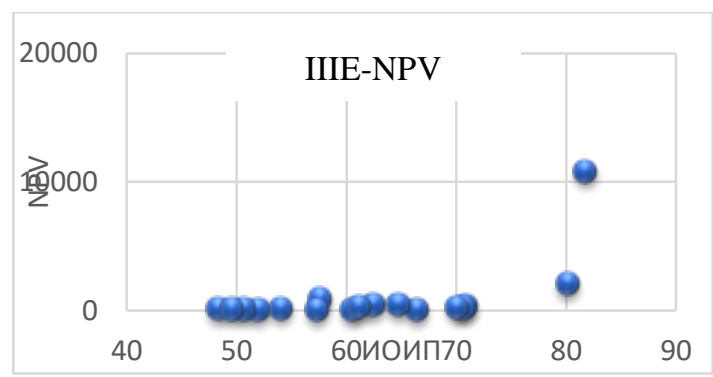

Fig. 3. REI net present value of renovation objects vs IIIE

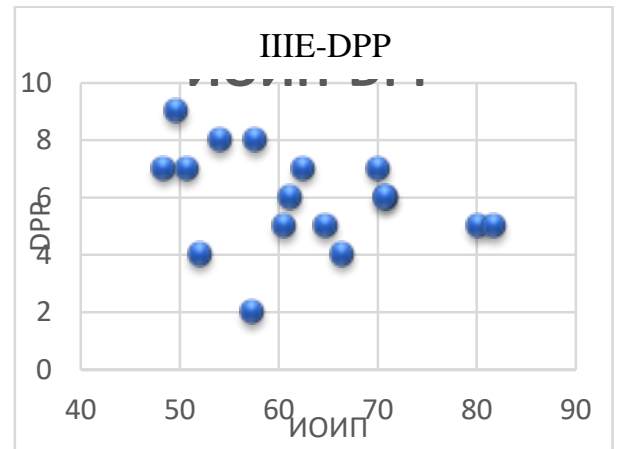

Fig. 4. REI discounted payback period of renovation objects vs. IIIE

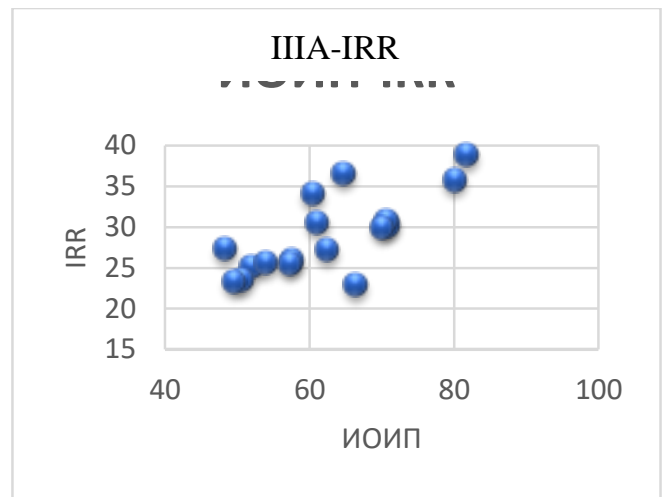

Fig. 5. REI internal rate of return of renovation objects vs. IIIE

\section{IIIA-RIRR}

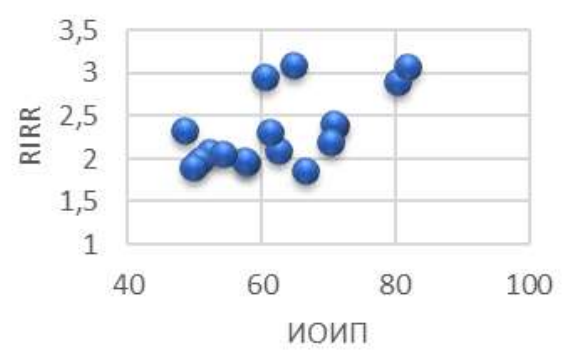

Fig. 6. REI indicator of renovation reliability of renovation objects vs. IIIE

After analyzing the specifics of the application of stochastic methods of factor analysis, we determined the need to identify the tightness of the relationship between the studied technical and town-planning factors of the investment attractiveness of real estate renovation by means of a correlation analysis [4].

Since many different factors are studied in the framework of the study, it is advisable to apply the analysis of multiple correlation.

Using Microsoft Excel tools, we determined the correlation coefficients for our factors. As input, for $y$ we took the total indicators of the risk group, for $\mathrm{x}$ we took the total rating weights for each group of factors (Table 2).

Applying the formula for calculating the matrix of pair correlation coefficients at the output, we obtain the following correlation indicators (Table 3).

Thus, having determined the indicators of multiple correlation coefficients, we established an insignificant mathematical correlation of factors among themselves, which indicates a low degree of interconnection and the absence of a close relationship between the studied groups of urban planning and technical indicators of investment attractiveness of real estate renovation. A correlation analysis of the factors included in the regression equation confirms a low level of autocorrelation - the relationship between obviously independent source data. This circumstance allows building statistically reliable regression models based on the selected technical and urban planning characteristics of real estate renovation [5]. 
TABLE II. INPUT PARAMETERS OF MULTIPLE CORRELATION ANALYSIS

\begin{tabular}{|l|l|l|l|l|l|l|l|l|l|l|}
\hline \multirow{2}{*}{$\begin{array}{c}\text { Object } \\
\text { No. }\end{array}$} & \multicolumn{10}{|c|}{ Technical and urban planning factors of renovation } \\
\cline { 2 - 12 } & $\boldsymbol{P}_{\boldsymbol{1}}$ & $\boldsymbol{P}_{\mathbf{2}}$ & $\boldsymbol{P}_{\mathbf{3}}$ & $\boldsymbol{P}_{\mathbf{4}}$ & $\boldsymbol{P}_{\boldsymbol{5}}$ & $\boldsymbol{P}_{\boldsymbol{6}}$ & $\boldsymbol{P}_{\boldsymbol{7}}$ & $\boldsymbol{P}_{\boldsymbol{8}}$ & $\boldsymbol{P}_{\boldsymbol{9}}$ & $\boldsymbol{P}_{\boldsymbol{1}}$ \\
\hline 1 & 90 & 80 & 20 & 20 & 100 & 40 & 90 & 20 & 20 & 100 \\
\hline 2 & 100 & 60 & 20 & 40 & 20 & 60 & 60 & 40 & 30 & 100 \\
\hline 3 & 100 & 60 & 20 & 40 & 20 & 60 & 60 & 40 & 30 & 20 \\
\hline 4 & 90 & 70 & 20 & 60 & 20 & 60 & 80 & 40 & 20 & 100 \\
\hline 5 & 90 & 70 & 20 & 60 & 20 & 60 & 80 & 40 & 20 & 80 \\
\hline 6 & 80 & 60 & 10 & 80 & 10 & 60 & 60 & 20 & 30 & 80 \\
\hline 7 & 70 & 70 & 20 & 60 & 40 & 80 & 60 & 60 & 30 & 80 \\
\hline 8 & 80 & 50 & 70 & 60 & 80 & 90 & 50 & 20 & 80 & 80 \\
\hline 9 & 100 & 60 & 80 & 100 & 100 & 80 & 90 & 0 & 40 & 80 \\
\hline 10 & 90 & 60 & 100 & 100 & 100 & 80 & 80 & 0 & 50 & 80 \\
\hline 11 & 80 & 60 & 30 & 100 & 70 & 60 & 60 & 40 & 20 & 100 \\
\hline 12 & 80 & 60 & 80 & 100 & 80 & 60 & 80 & 40 & 20 & 80 \\
\hline 13 & 40 & 55 & 70 & 80 & 90 & 80 & 60 & 20 & 70 & 80 \\
\hline 14 & 80 & 65 & 40 & 100 & 10 & 80 & 70 & 40 & 40 & 80 \\
\hline 15 & 80 & 60 & 20 & 60 & 20 & 60 & 60 & 20 & 40 & 80 \\
\hline 16 & 90 & 70 & 30 & 80 & 50 & 80 & 70 & 60 & 50 & 80 \\
\hline 17 & 70 & 50 & 70 & 80 & 70 & 20 & 80 & 40 & 20 & 100 \\
\hline
\end{tabular}

a. $\mathrm{P}_{1}-$ Urban Development Potential

${ }^{\text {b. }} \mathrm{P}_{2}$ - Percentage of Wear

${ }^{c} \mathrm{P}_{3}-$ Design and space-planning characteristics of the building

$$
{ }^{\text {d. }} \mathrm{P}_{4} \text { - Floor of the building }
$$

e. $\mathrm{P}_{5}-$ Construction volum

${ }^{\text {f. }} \mathrm{P}_{6}-$ Building density

g. $P_{7}-$ Infrastructure Status

h. $\mathrm{P}_{8}-$ Ecological situation

${ }^{\text {i. }} \mathrm{P}_{9}-$ Territorial potentia

j. $\mathrm{P}_{10}$ - Engineering network

k. $P_{i}$ corresponds to the serial number of the factor space of the renovation of real estate.

TABLE III. CALCULATION OF CORRELATION COEFFICIENTS

\begin{tabular}{|l|l|l|l|l|l|l|l|l|l|l|}
\hline & \multicolumn{1}{|c|}{$\mathbf{P}_{\mathbf{1}}$} & $\mathbf{P}_{\mathbf{2}}$ & $\mathbf{P}_{\mathbf{3}}$ & $\mathbf{P}_{\mathbf{4}}$ & $\mathbf{P}_{\mathbf{5}}$ & $\mathbf{P}_{\mathbf{6}}$ & $\mathbf{P}_{\mathbf{7}}$ & $\mathbf{P}_{\mathbf{8}}$ & $\mathbf{P}_{\mathbf{9}}$ & $\mathbf{P}_{\mathbf{1 0}}$ \\
\hline $\mathrm{P}_{1}$ & 1 & & & & & & & & & \\
\hline $\mathrm{P}_{2}$ & 0.26 & 1 & & & & & & & & \\
\hline $\mathrm{P}_{3}$ & 0.18 & 0.50 & 1 & & & & & & & \\
\hline $\mathrm{P}_{4}$ & 0.23 & 0.38 & 0.59 & 1 & & & & & & \\
\hline $\mathrm{P}_{5}$ & 0.18 & 0.13 & 0.74 & 0.24 & 1 & & & & & \\
\hline $\mathrm{P}_{6}$ & 0.31 & 0.49 & 0.56 & 0.50 & 0.2 & 1 & & & & \\
\hline $\mathrm{P}_{7}$ & 0.38 & 0.58 & 0.24 & 0.11 & 0.36 & 0.29 & 1 & & & \\
\hline $\mathrm{P}_{8}$ & 0.02 & 0.38 & 0.56 & 0.19 & 0.52 & 0.07 & 0.27 & 1 & & \\
\hline $\mathrm{P}_{9}$ & 0.43 & 0.60 & 0.52 & 0.17 & 0.34 & 0.77 & 0.42 & 0.34 & 1 & \\
\hline $\mathrm{P}_{10}$ & 0.12 & 0.27 & 0.03 & 0.08 & 0.19 & 0.15 & 0.236 & 0.04 & 0.14 & 1 \\
\hline
\end{tabular}

The essence of the regression analysis is to describe the "technology" of the influence of factors, i.e. the signs on the results of calculating investment indicators, which in a specific task acts as an object of management.

Regression analysis includes a theoretical synthesis of the nature of the phenomenon under study in order to identify a range of factors that affect the behavior of the resulting investment spaces. Taking into account the low level of autocorrelation of multiple correlation analysis, we found the validity of further statistical support for the connection of the factor space with investment indicators of economic efficiency of renovation under specific project conditions, while discarding those investment indicators that to a greater extent did not reflect the specifics of portfolio investment implementation with the multivariance of REI renovation. Here, we construct the regression equation, which under certain conditions can be recognized as a statistical model of the relationship of existing signs [6].

Using Microsoft Excel tools, using the built-in functions and LINEST formulas, the author obtained the coefficients of the linear multiple regression equation using the least squares method (Table 5). Input parameters are shown in Table 4.

TABLE IV. INPUT PARAMETERS FOR EVALUATING MULTIPLE REGRESSION ANALYSIS ACCORDING TO THE PROFITABILITY INDICATOR REI RENOVATION

\begin{tabular}{|l|l|l|l|l|l|l|l|l|l|l|}
\hline \multirow{2}{*}{ DPI } & \multicolumn{10}{|c|}{ Technical and urban planning factors of renovation } \\
\cline { 2 - 11 } & $\boldsymbol{P}_{\boldsymbol{1}}$ & $\boldsymbol{P}_{\boldsymbol{2}}$ & $\boldsymbol{P}_{\boldsymbol{3}}$ & $\boldsymbol{P}_{\boldsymbol{4}}$ & $\boldsymbol{P}_{\boldsymbol{5}}$ & $\boldsymbol{P}_{\boldsymbol{6}}$ & $\boldsymbol{P}_{\boldsymbol{7}}$ & $\boldsymbol{P}_{\boldsymbol{8}}$ & $\boldsymbol{P}_{\boldsymbol{9}}$ & $\boldsymbol{P}_{\boldsymbol{1 0}}$ \\
\hline 2.22 & 90 & 80 & 20 & 20 & 100 & 40 & 90 & 20 & 20 & 100 \\
\hline 2.65 & 100 & 60 & 20 & 40 & 20 & 60 & 60 & 40 & 30 & 100 \\
\hline 1.9 & 100 & 60 & 20 & 40 & 20 & 60 & 60 & 40 & 30 & 20 \\
\hline 1.79 & 90 & 70 & 20 & 60 & 20 & 60 & 80 & 40 & 20 & 100 \\
\hline 2.15 & 90 & 70 & 20 & 60 & 20 & 60 & 80 & 40 & 20 & 80 \\
\hline 1.9 & 80 & 60 & 10 & 80 & 10 & 60 & 60 & 20 & 30 & 80 \\
\hline 2.31 & 70 & 70 & 20 & 60 & 40 & 80 & 60 & 60 & 30 & 80 \\
\hline 2.84 & 80 & 50 & 70 & 60 & 80 & 90 & 50 & 20 & 80 & 80 \\
\hline 3.64 & 100 & 60 & 80 & 100 & 100 & 80 & 90 & 0 & 40 & 80 \\
\hline 3.96 & 90 & 60 & 100 & 100 & 100 & 80 & 80 & 0 & 50 & 80 \\
\hline 2.38 & 80 & 60 & 30 & 100 & 70 & 60 & 60 & 40 & 20 & 100 \\
\hline 2.86 & 80 & 60 & 80 & 100 & 80 & 60 & 80 & 40 & 20 & 80 \\
\hline 2.55 & 40 & 55 & 70 & 80 & 90 & 80 & 60 & 20 & 70 & 80 \\
\hline 3.66 & 80 & 65 & 40 & 100 & 10 & 80 & 70 & 40 & 40 & 80 \\
\hline 2.08 & 80 & 60 & 20 & 60 & 20 & 60 & 60 & 20 & 40 & 80 \\
\hline 3.89 & 90 & 70 & 30 & 80 & 50 & 80 & 70 & 60 & 50 & 80 \\
\hline 2.75 & 70 & 50 & 70 & 80 & 70 & 20 & 80 & 40 & 20 & 100 \\
\hline
\end{tabular}

TABLE V. LEAST SQUARES REGRESSION COEFFICIENT DETERMINATION

\begin{tabular}{|c|c|c|c|c|c|c|c|c|}
\hline & Coefficients & Standard error & t-statistic & P-value & Lower $95 \%$ & Upper $95 \%$ & Lower $95.0 \%$ & Upper $95.0 \%$ \\
\hline$Y$ & 0 & $\# \boldsymbol{H} / \boldsymbol{A}$ & \#Н/Д & $\# \boldsymbol{H} / Д$ & $\#$ \#/Д & \#Н/Д & \#Н/Д & \#Н/Д \\
\hline $\mathrm{P}_{1}$ & 0.01013 & 0.0119 & 0.847 & 0.4247 & -0.018 & 0.038 & -0.0181 & 0.038 \\
\hline $\mathrm{P}_{2}$ & -0.0256 & 0.0545 & -0.468 & 0.6534 & -0.154489 & 0.1034 & -0.154 & 0.1034 \\
\hline $\mathrm{P}_{3}$ & 0.00179 & 0.0197 & 0.090 & 0.9303 & -0.0449 & 0.0485 & -0.044 & 0.0484 \\
\hline $\mathrm{P}_{4}$ & 0.00835 & 0.0101 & 0.820 & 0.43887 & -0.0157 & 0.032 & -0.015 & 0.0324 \\
\hline $\mathrm{P}_{5}$ & 0.00296 & 0.0089 & 0.331 & 0.74980 & -0.0181 & 0.024 & -0.018 & 0.0240 \\
\hline $\mathrm{P}_{6}$ & 0.00727 & 0.0216 & 0.335 & 0.74710 & -0.0439 & 0.058 & -0.043 & 0.0584 \\
\hline $\mathrm{P}_{7}$ & 0.02007 & 0.0387 & 0.518 & 0.62005 & -0.0714 & 0.111 & -0.071 & 0.1115 \\
\hline $\mathrm{P}_{8}$ & 0.0097 & 0.0124 & 0.783 & 0.45886 & -0.0195 & 0.038 & -0.019 & 0.0389 \\
\hline $\mathrm{P}_{9}$ & 0.0126 & 0.017 & 0.719 & 0.49535 & -0.0286 & 0.053 & -0.028 & 0.0536 \\
\hline $\mathrm{P}_{10}$ & -0.0002 & 0.009 & -0.0258 & 0.98009 & -0.0223 & 0.022 & -0.022 & 0.0218 \\
\hline
\end{tabular}


Profitability. With the following statistical security:

\section{Normalized $\mathrm{R}_{2}=0.812$}

The significance of $F=0.00016$ for the constructed equation is significantly less than the significance level of 0.05 , which confirms the validity of the regression.

$$
\begin{gathered}
\mathrm{DPI}=0.010131671 \mathrm{P} 1-0.02556414 \mathrm{P}_{2}+0.001789475 \mathrm{P}_{3}+ \\
+0.008349857 \mathrm{P}_{4}+0.002956373 \mathrm{P}_{5}+0.007266355 \mathrm{P}_{6}+ \\
+0.020067259 \mathrm{P}_{7}+0.009687289 \mathrm{P}_{8}+ \\
+0.012505946 \mathrm{P}_{9}-0.000241225 \mathrm{P}_{10}
\end{gathered}
$$

The indicators of the statistical significance of the obtained regression equation suggest the feasibility and sufficiency of the set of technical and town-planning characteristics of the renovation object accepted for analysis to obtain reliable estimates of the potential capitalization of renovation REI of real estate.

After the regression equation is found, the quality of the obtained link equation, as well as its parameters, is estimated. To check the significance of the regression equation is to establish how the mathematical model expressing the statistical dependence between the variables corresponds to the experimental data and whether there are enough variables included to describe their mathematical dependence. We will analyze the regression equation using the Microsoft Excel tool, using the built-in "REGRESSION" data analysis. The data obtained are reflected in Tables 6 and 7.

TABLE VI. ANALYSIS OF VARIANCE

\begin{tabular}{|l|c|c|c|c|c|}
\hline Analysis of variance & & & & \\
\hline & $\boldsymbol{d} \boldsymbol{f}$ & $\boldsymbol{S S}$ & $\boldsymbol{M S}$ & $\boldsymbol{F}$ & Significance $\boldsymbol{F}$ \\
\hline Variance & 10 & 127.50853 & 12.75085 & 34.52881 & 0.00016564 \\
\hline Remainder & 7 & 2.5849711 & 0.369282 & & \\
\hline Total & 17 & 130.0935 & & & \\
\hline
\end{tabular}

The significance of the equation as a whole is based on the Fisher F-criterion - the ratio of the factor dispersion of the result attribute calculated for one degree of freedom to the residual variance to the resultant characteristic for one degree of freedom. Accordingly, the Fisher test for multiple regression has the following form:

$$
F=\frac{R^{2}}{1-R^{2}} \times \frac{n-m-1}{n},
$$

where $n-$ is the number of observations (17); $m$ is the number of factors (10);

$R$ is the multiple correlation coefficient.

The actual value of the Fisher F-test value is compared with the table. $\mathrm{F}_{\mathrm{tabl}}=34.52$, therefore $\mathrm{F}_{\mathrm{tabl}}=34.52>\mathrm{F}=0.00016$, hence the conclusion about the statistical significance of the resulting equation. The probability of accidentally obtaining such an F-criterion value does not exceed an acceptable significance level of $5 \%$.

The significance of the regression coefficients is estimated by the parameter $\mathrm{t}$ (Student's criterion).

The actual value of the Student criterion, as well as the Fisher criterion, is compared with a table value. Parameters are considered statistically significant if $t_{\text {actual }}>t_{\text {tabl }}$.

TABLE VII. REGRESSION STATISTICS

\begin{tabular}{|l|l|}
\hline Multiple R & 0.9900151 \\
\hline R squared & 0.980129898 \\
\hline Normalized R squared & 0.811725481 \\
\hline Standard error & 0.607685433 \\
\hline Observations & 17 \\
\hline
\end{tabular}

Thus, the constructed multiple linear regression describes the initial data well and can be used to further predict the estimated profitability indicators of the renovation REI.

\begin{tabular}{|c|c|c|c|c|c|c|c|c|}
\hline & Coefficients & Standard error & t-statistic & P-value & Lower 95\% & Upper $95 \%$ & Lower $95.0 \%$ & Upper $95.0 \%$ \\
\hline$Y$ & 0 & $n / d$ & $n / d$ & $n / d$ & $n / d$ & $n / d$ & $n / d$ & $n / d$ \\
\hline $\mathrm{P}_{1}$ & 0.1088 & 0.0597 & 1.8216 & 0.1112 & -0.0324 & 0.2501 & -0.0324 & 0.2501 \\
\hline $\mathrm{P}_{2}$ & 0.0857 & 0.2724 & 0.3143 & 0.7623 & -0.5586 & 0.7299 & -0.5586 & 0.7299 \\
\hline $\mathrm{P}_{3}$ & 0.0501 & 0.0987 & 0.5071 & 0.6276 & -0.1833 & 0.2834 & -0.1833 & 0.2834 \\
\hline $\mathrm{P}_{4}$ & 0.1072 & 0.0508 & 2.1083 & 0.0729 & -0.0130 & 0.2274 & -0.0130 & 0.2274 \\
\hline $\mathrm{P}_{5}$ & 0.0235 & 0.0445 & 0.5266 & 0.6147 & -0.0818 & 0.1287 & -0.0818 & 0.1287 \\
\hline $\mathrm{P}_{6}$ & -0.0708 & 0.1082 & -0.6537 & 0.5341 & -0.3267 & 0.1851 & -0.3267 & 0.1851 \\
\hline $\mathrm{P}_{7}$ & 0.0317 & 0.1933 & 0.1638 & 0.8744 & -0.4256 & 0.4889 & -0.4256 & 0.4889 \\
\hline $\mathrm{P}_{8}$ & 0.0561 & 0.0617 & 0.9082 & 0.3939 & -0.0899 & 0.2021 & -0.0899 & 0.2021 \\
\hline $\mathrm{P}_{9}$ & 0.1666 & 0.0869 & 1.9165 & 0.0968 & -0.0389 & 0.3720 & -0.0389 & \begin{tabular}{|l|}
0.3720 \\
\end{tabular} \\
\hline $\mathrm{P}_{10}$ & -0.0212 & 0.0466 & -0.4550 & 0.6628 & -0.1314 & 0.0891 & -0.1314 & 0.08902 \\
\hline
\end{tabular}

TABLE VIII. INPUT PARAMETERS FOR ASSESSING MULTIPLE REGRESSION ANALYSIS BY THE INDICATOR OF INTERNAL RATE OF RETURN RENOVATION REI

\begin{tabular}{|l|l|l|l|l|l|l|l|l|l|l|}
\hline \multirow{2}{*}{ IRR } & \multicolumn{7}{|c|}{ Technical and urban planning factors of renovation } \\
\cline { 2 - 11 } & $\boldsymbol{P}_{\boldsymbol{1}}$ & $\boldsymbol{P}_{\boldsymbol{2}}$ & $\boldsymbol{P}_{\boldsymbol{3}}$ & $\boldsymbol{P}_{\boldsymbol{4}}$ & $\boldsymbol{P}_{\boldsymbol{5}}$ & $\boldsymbol{P}_{\boldsymbol{6}}$ & $\boldsymbol{P}_{\boldsymbol{7}}$ & $\boldsymbol{P}_{\boldsymbol{8}}$ & $\boldsymbol{P}_{\boldsymbol{9}}$ & $\boldsymbol{P}_{\boldsymbol{1} \boldsymbol{0}}$ \\
\hline 25.9 & 90 & 80 & 20 & 20 & 100 & 40 & 90 & 20 & 20 & 100 \\
\hline 27.3 & 100 & 60 & 20 & 40 & 20 & 60 & 60 & 40 & 30 & 100 \\
\hline 25.1 & 100 & 60 & 20 & 40 & 20 & 60 & 60 & 40 & 30 & 20 \\
\hline 22.9 & 90 & 70 & 20 & 60 & 20 & 60 & 80 & 40 & 20 & 100 \\
\hline 23.5 & 90 & 70 & 20 & 60 & 20 & 60 & 80 & 40 & 20 & 80 \\
\hline 25.5 & 80 & 60 & 10 & 80 & 10 & 60 & 60 & 20 & 30 & 80 \\
\hline 25.6 & 70 & 70 & 20 & 60 & 40 & 80 & 60 & 60 & 30 & 80 \\
\hline 30.2 & 80 & 50 & 70 & 60 & 80 & 90 & 50 & 20 & 80 & 80 \\
\hline 35.71 & 100 & 60 & 80 & 100 & 100 & 80 & 90 & 0 & 40 & 80 \\
\hline 38.8 & 90 & 60 & 100 & 100 & 100 & 80 & 80 & 0 & 50 & 80 \\
\hline 27.2 & 80 & 60 & 30 & 100 & 70 & 60 & 60 & 40 & 20 & 100 \\
\hline 30.7 & 80 & 60 & 80 & 100 & 80 & 60 & 80 & 40 & 20 & 80 \\
\hline 29.9 & 40 & 55 & 70 & 80 & 90 & 80 & 60 & 20 & 70 & 80 \\
\hline 34 & 80 & 65 & 40 & 100 & 10 & 80 & 70 & 40 & 40 & 80 \\
\hline 23.3 & 80 & 60 & 20 & 60 & 20 & 60 & 60 & 20 & 40 & 80 \\
\hline 36.5 & 90 & 70 & 30 & 80 & 50 & 80 & 70 & 60 & 50 & 80 \\
\hline 30.5 & 70 & 50 & 70 & 80 & 70 & 20 & 80 & 40 & 20 & 100 \\
\hline
\end{tabular}

TABLE IX. LEAST SQUARES REGRESSION COEFFICIENT DETERMINATION 
Internal rate of return. With the following statistical security:

\section{Normalized $\mathrm{R}_{2}=0.847$}

The significance of $F=0.000002$ for the constructed equation is significantly less than the significance level of 0.05 , which confirms the validity of the regression.

$\mathrm{IRR}=0.10883 \mathrm{P}_{1}+0.08566 \mathrm{P}_{2}+0.05006 \mathrm{P}_{3}+0.1072 \mathrm{P}_{4}+0.02346 \mathrm{P}_{5}-$

$$
-0.0708 \mathrm{P}_{6}+0.03169 \mathrm{P}_{7}+0.0561 \mathrm{P}_{8}+0.16656 \mathrm{P}_{9}-0.0212 \mathrm{P}_{10}
$$

The indicators of the statistical significance of the obtained regression equation suggest the feasibility and sufficiency of the set of technical and urban planning characteristics of the renovation object accepted for analysis to obtain reliable estimates of the potential capitalization of renovation REI of real estate [7].

After the regression equation is found, the quality of the obtained link equation, as well as its parameters, is estimated. To check the significance of the regression equation is to establish how the mathematical model expressing the statistical dependence between the variables corresponds to the experimental data and whether there are enough variables included to describe their mathematical dependence. We will analyze the regression equation using the Microsoft Excel tool, using the built-in "REGRESSION" data analysis. The data obtained are reflected in Tables 10 and 11.

The significance of the equation as a whole is based on the Fisher F-criterion - the ratio of the factor dispersion of the result attribute calculated for one degree of freedom to the residual variance to the resultant characteristic for one degree of freedom, thus the Fisher test for multiple regression has the following form:

$$
F=\frac{R^{2}}{1-R^{2}} \times \frac{n-m-1}{n}
$$

where $n-$ is the number of observations (17);

$m$ is the number of factors (10);

$R$ is the multiple correlation coefficient.

TABLE $X$

\begin{tabular}{|c|c|c|c|c|c|}
\hline \multicolumn{3}{|c|}{ Analysis of variance } & & & \\
\hline & $d f$ & $S S$ & $M S$ & $F$ & Significance $F$ \\
\hline Variance & 10 & 14594.2358 & 1459.423576 & 158.2439 & $1.86502 \mathrm{E}-06$ \\
\hline Remainder & 7 & 64.5583447 & 9.222620669 & & \\
\hline Total & 17 & 14658.7941 & & & \\
\hline
\end{tabular}

ANALYSIS OF VARIANCE

The actual value of the Fisher F-test is compared with the table. $\mathrm{F}_{\text {tabl }}=158.24$, therefore $\mathrm{F}_{\mathrm{tabl}}=158.24>\mathrm{F}_{\mathrm{tabl}}=0.000002$, hence the conclusion about the statistical significance of the resulting equation. The probability of accidentally obtaining such an F-criterion value does not exceed an acceptable significance level of $5 \%$.

The significance of the regression coefficients is estimated by the parameter $\mathrm{t}$ - Student's criterion.

The actual value of the Student criterion, as well as the Fisher test value, is compared with a table value. Parameters are considered statistically significant if $t_{a c t} u a l>t_{t a b l}$.
TABLE XI. REGRESSION STATISTICS

\begin{tabular}{|l|l|}
\hline Multiple R & 0.9978 \\
\hline R squared & 0.9956 \\
\hline Normalized R squared & 0.84708 \\
\hline Standard error & 3.03688 \\
\hline Observations & 17 \\
\hline
\end{tabular}

Thus, the constructed multiple linear regression fairly describes the initial data and can be used for further forecasting the calculated indicators of the internal rate of return of renovation REI.

The main qualitative characteristics of the identified dependencies of the indicators of economic efficiency of renovation from the technical and urban characteristics of real estate objects confirm the consistency of the proposed methodology for assessing the effectiveness of investments in renovation of real estate. Of particular interest is a qualitative examination of the main dependences of profitability and internal rate of return on the value of factor space points, which allows assessing the degree of influence of individual technical and town-planning characteristics of renovated buildings on their potential capitalization and identify key areas for increasing the efficiency of portfolio investments in a group of real estate [8].

To quantify the value of the economic sustainability of the investment renovation project, it is proposed to introduce the rate of investment reliability of the renovation calculated by the formula: $\mathrm{RIRR}=\mathrm{DIRR} / \mathrm{R}_{\mathrm{ren}}$

TABLE XII. DEPENDENCE OF ECONOMIC EFFICIENCY LEVEL ON RIRR

\begin{tabular}{|l|l|}
\hline RIRR variation Interval & \multicolumn{1}{|c|}{$\begin{array}{c}\text { Economic efficiency level of renovation } \\
\text { construction investment project }\end{array}$} \\
\hline RIRR $<1.1$ & Inefficient \\
\hline $1.1<\mathrm{RIRR}<1.5$ & Slightly efficient \\
\hline $1.5<\mathrm{RIRR}<2$ & Moderately efficient \\
\hline $2.0<\mathrm{RIRR}<2.5$ & Efficient \\
\hline $2.5<\mathrm{RIRR}$ & Highly efficient \\
\hline
\end{tabular}

A convolution of criteria for the final ranking of REI by the degree of investment attractiveness and capitalization is applicable to a convolution of the ranking of objects according to two regression analyzed indicators of investment efficiency DPI and DIRR

$$
\mathrm{MV}_{\mathrm{u}}=\mathrm{PDI} * \mathrm{KDPI}+\mathrm{PDIRR} * \mathrm{KDIRR},
$$

where $M V_{u}$ is the final rank of REI for the total investment attractiveness of renovation

PDPI is REI investment capacity (REI rank of investment attractiveness in terms of profitability)

\section{KDPI is investment performance weighting factor}

PDIRR is REI investment reliability (REI rank of investment attractiveness in terms of internal rate of return)

\section{KDIRR is Investment Reliability Weights}

It is recommended to use the following initial values of the weighting factors of investment capacity and reliability in the process of actual convolution of the ranking places of investment alternatives of Table 13 
TABLE XIII. WEIGHTING RATIOS OF INVESTMENT CAPACITY AND RELIABILITY

\begin{tabular}{|l|l|l|}
\hline \multicolumn{1}{|c|}{ Investment portfolio characteristics } & $\mathbf{K}_{\mathbf{P I}^{-}}$ & $\mathbf{K}_{\mathbf{I R R}}$ \\
\hline $\begin{array}{l}\text { Medium and long-term capitalization-based venture } \\
\text { capitalization }\end{array}$ & 0.25 & 0.75 \\
\hline $\begin{array}{l}\text { Savings, orientated and short- and medium-term } \\
\text { capitalization effect }\end{array}$ & 0.75 & 0.25 \\
\hline $\begin{array}{l}\text { Mixed, presented by REI of various types of } \\
\text { investment }\end{array}$ & 0.5 & 0.5 \\
\hline
\end{tabular}

TABLE XIV. RESULTS OF THE CONVOLUTION OF THE CRITERIA OF THE STUDIED RENOVATION OBJECTS

\begin{tabular}{|l|l|l|l|l|}
\hline Object No. & \multicolumn{1}{|c|}{ IIIE } & \multicolumn{1}{|c|}{ Venture } & \multicolumn{1}{c|}{ Savings } & \multicolumn{1}{c|}{ Mixed } \\
\hline 1 & 57.7 & 19.98 & 8.14 & 14.06 \\
\hline 2 & 48.45 & 21.14 & 8.81 & 14.97 \\
\hline 3 & 52.1 & 19.3 & 7.7 & 13.5 \\
\hline 4 & 66.5 & 17.62 & 7.06 & 12.34 \\
\hline 5 & 50.8 & 18.16 & 7.48 & 12.82 \\
\hline 6 & 57.4 & 19.6 & 7.8 & 13.7 \\
\hline 7 & 54.15 & 19.77 & 8.13 & 13.95 \\
\hline 8 & 70.95 & 23.36 & 9.68 & 16.52 \\
\hline 9 & 80.25 & 27.69 & 11.65 & 19.67 \\
\hline 10 & 81.85 & 30.09 & 12.67 & 21.38 \\
\hline 11 & 62.55 & 20.99 & 8.58 & 14.79 \\
\hline 12 & 70.8 & 23.74 & 9.82 & 16.78 \\
\hline 13 & 70.15 & 23.06 & 9.38 & 16.22 \\
\hline 14 & 60.6 & 26.41 & 11.24 & 18.83 \\
\hline 15 & 49.7 & 17.99 & 7.38 & 12.69 \\
\hline 16 & 64.85 & 28.34 & 12.04 & 20.19 \\
\hline 17 & 61.25 & 23.56 & 9.68 & 16.62 \\
\hline
\end{tabular}

In the process of acquiring investment experience and replenishing the database of implemented projects, the investor is entitled to adjust the coefficients presented in Table 13 based on the nature of investment preferences [9].

\section{CONCLUSIONS}

As a result of the proposed criteria convolution technique, a full-scale experiment was carried out realizing the final ranking of the renovation REI by the degree of investment attractiveness and capitalization, as a result of which the viability of the proposed methodology was established. The results of the full-scale experiment of the methodology for convolution of criteria clearly reflect the value of investment attractiveness and capitalization of one renovation REI in relation to another with the multivariance of alternatives for choosing the best renovation REI.
Thus, the general conclusion is that, having carried out a factor analysis of the influence of factor space on the investment attractiveness of real estate renovation, a close relationship between the variables of factors and investment indicators, and the most significant investment indicators were revealed, taking into account their convolution and further ranking, and based on them, we conducted a statistical assessment, which confirmed the nonrandom distribution of the obtained parameters.

\section{Acknowledgment}

This work was realized under support of the President Scholarship; in the framework of the Program of flagship university development on the base of the Belgorod State Technological University named after V G Shukhov

\section{References}

[1] I.P. Avilova, I.S. Zharikov, "Methodology for assessing the investment attractiveness of the reconstruction of a publication (structure) for its subsequent implementation as a commercial, residential or social property", Econ. and Entrepreneurship, vol. 4-1, no. 57-1, pp. 966-971, 2015

[2] I.P. Avilova, I.S. Zharikov, "Methodology for constructing a cumulative integrated indicator of the risk environment of investment projects for the reconstruction of real estate", Bull. of BSTU named after V.G. Shukhov, no. 6, pp. 220-225, 2016.

[3] D. Yudin, A. Naumov, A. Dolzhenko, E. Patrakova, N. Shirina, "Software for roof defects recognition on aerial photographs", J. of Phys.: Conf. Ser., vol. 1015, p. 032152, 2018

[4] I.P. Avilova, M.O. Krutilova, "Methodology of ecooriented assessment of constructive schemes of cast in-situ rc framework in civil engineering", IOP Conf. Ser. Earth and Environmental Sci., p. 012127, 2018.

[5] I. Avilova, M. Krutilova, E. Peresypkina, "Economic incentives of green standards in civil and municipal engineering", Ecol., Econ., Ed. and Legislat., pp. 273-280, 2017.

[6] P.G. Grabovy, A.E. Naumov, I.P. Avilova, "Scientific aspects of productivity management in the investment and construction sector", Int Busin. Manag., vol. 10, no. 7, pp. 1354-1364, 2016.

[7] I.P. Avilova, A.E. Naumov, M.A. Shchenyatskaya, "Improving the economic efficiency of construction investments by means of technological risks management", J. of Fundam. and Appl. Sci., vol. 8, no. S2, pp. 1502-1518, 2016

[8] R.G. Abakumov, I.P. Avilova, I.V. Ursu, E.O. Kapustina, "Methodical toolkit of managing reproduction of the fixed assets of an organization", J. of the Soc. Sci., vol. 10, p. 1449, 2015.

[9] P.G. Grabovyi, I.P. Avilova, "The empiric methodology of evaluating and managing the aggregate risk at implementing large complex building and investment projects abroad", Life Sci. J., vol. 11, no. 12s, pp. 610-615, 2014. 